\title{
AVALIAÇÃO NOS ANOS INICIAIS DO ENSINO FUNDAMENTAL: Perspectivas de Professores de Educação Física
}

\author{
Thalita Fernanda de Oliveira Macedo ${ }^{1}$ \\ Lílian Aparecida Ferreira²
}

\begin{abstract}
RESUMO
Este artigo buscou identificar e analisar as perspectivas de professores de Educação Física sobre a avaliação de alunos dos anos iniciais do Ensino Fundamental. A pesquisa orientou-se pela abordagem qualitativa de investigação a partir de um estudo exploratório, no qual foram entrevistados 30 professores de Educação Física atuantes nos anos iniciais do Ensino Fundamental. A pesquisa revelou que os professores, nas aulas de Educação Física escolar, destacaram, no que diz respeito às práticas avaliativas, os conhecimentos conceituais, procedimentais e atitudinais, com um predomínio dos atitudinais em relação aos outros dois. Adicionalmente, manifestaram relacionar a avaliação de elementos correspondentes às questões corporais nas aulas de Educação Física, envolvendo um saber fazer dos alunos vinculados ao movimento, bem como um saber sobre esse fazer, valorizando a compreensão, a reflexão e a análise. As considerações acerca de todo este processo revelaram uma ampliação de sentido e ações avaliativas por parte dos professores de Educação Física, podendo sinalizar, para a área, uma possível reconfiguração alinhada aos pressupostos da cultura corporal de movimento.
\end{abstract}

Palavras-chave: Avaliação. Educação Física escolar. Ensino Fundamental.

\section{EVALUATION DURING THE FIRST YEARS OF PRIMARY SCHOOL: PERSPECTIVES FROM PHYSICAL EDUCATION TEACHERS}

\begin{abstract}
This article has attempted to identify and analyze the perspectives of Physical Education teacher about the evaluation of the first years of Primary School. The research was guided by the qualitative method of investigative research, based on an exploratory study, in which 30 Physical Education teachers working on the first years of primary education were interviewed. The research has revealed that the teachers, during the Physical Education classes at school, within the evaluation practices, have highlighted conceptual, procedural and attitudinal knowledge, with a predominance of the attitudinal ones in relation to the others. Additionally, they manifested that they relate the evaluation of elements corresponding the matters of body movement in Physical Education classes, involving a know-how of the students tied to the movement, as well as an attainment of this movement, valuing the comprehension, reflection and analysis. The considerations about this whole process have revealed an amplification of meaning and evaluative actions from the Physical Education teachers, which are able to signalize for this field of knowledge, a possible reconfiguration aligned to the presuppositions of the body movement culture.
\end{abstract}

Keywords: Evaluation. Physical Education at school. Primary education.

RECEBIDO EM: 12/12/2019

ACEITO EM: 20/3/2020

\footnotetext{
1 Autora correspondente. Universidade Estadual Paulista Júlio de Mesquita Filho - Unesp. Av. Engenheiro Luiz Edmundo Carrijo Coube, s/n. 17033-360 - Bauru/SP, Brasil. http://lattes.cnpq.br/9618374629771891. https://orcid.org/0000-0003-0300-6603. thalitika@hotmail.com

2 Universidade Estadual Paulista Júlio de Mesquita Filho - Unesp. Bauru/SP, Brasil. http://lattes.cnpq.br/5593652376712829. https://orcid. org/0000-0001-8517-4795.
} 
Podemos afirmar que, atualmente, a reconfiguração da Educação Física escolar brasileira vem se estabelecendo pelo consenso no uso dos termos cultura corporal, cultura corporal de movimento ${ }^{3}$ e cultura de movimento (BRACHT, 2010). Embora tais termos carreguem conceitos de bases teóricas nem sempre coincidentes, o deslocamento do foco da aptidão física e do desempenho motor para uma perspectiva centrada na cultura, ou seja, no reconhecimento de que as práticas corporais estão assentadas no campo das significações e dos sentidos, tem contribuído para fortalecer outros modos de pensar a Educação Física, particularmente a Educação Física escolar.

Apesar disso, conforme constatam González e Fensterseifer (2009, p. 12): “[...] a EF [Educação Física] se encontra 'entre o não mais e o ainda não', ou seja, entre uma prática docente na qual não se acredita mais, e outra que ainda se tem dificuldades de pensar e desenvolver".

Sob este ponto de vista, o que parece menos nebuloso para os professores de Educação Física da escola é que os conhecimentos que precisam ser desenvolvidos por este componente curricular devem ir além dos esportes, envolvendo, portanto, os jogos, as danças, as lutas, as ginásticas, as práticas em contato com a natureza, dentre outras manifestações que podem se transformar em conteúdo escolar.

Entendendo a Educação Física na condição de componente curricular que trata como objeto de ensino a cultura corporal de movimento, concordamos com Bracht (2010, p. 3), na medida em que "Isso vai ampliar em muito o conteúdo de ensino da Educação Física como disciplina escolar e indicar também uma mudança de sentido, de função para sua presença na escola". Desse modo, passa-se agora a entender o papel da Educação Física como o de introduzir os alunos no universo da cultura corporal de movimento, ou seja, propiciar a construção pelo aluno de um amplo acervo cultural, neste caso a cultura corporal de movimento.

Dentre estas mudanças para a área, a avaliação na Educação Física escolar, segundo Darido (2012), passou por diferentes orientações. A mais significativa delas, pelo seu tempo de permanência no ambiente escolar, foi denominada tradicional ou esportivista, pois esteve muito presente no Brasil a partir da década de 70 do século 20. Neste momento, predominavam preocupações avaliativas que enfatizavam a medição, o desempenho das capacidades físicas, as habilidades motoras e, em alguns casos, o uso das medidas antropométricas. A avaliação dos professores de Educação Física detinha-se apenas ao resultado final no desempenho do aluno em relação às práticas corporais. Os alunos não eram informados pelos professores sobre as avaliações pelas quais passavam, não eram explicados os objetivos dos testes e tampouco havia vinculação entre estes e o programa de ensino desenvolvido ao longo do ano. Associado a este cenário, os estudantes eram submetidos aos testes e muitos ao sentimento de incompetência e

\footnotetext{
Cultura Corporal de Movimento é o termo que buscou estabelecer uma ponte entre os conceitos de cultura corporal e cultura de movimento, numa tentativa de reincorporar ou reconciliar o corpo e o movimento com a simbologia que neles comunica o ser humano com o seu mundo, considerando a dimensão histórico-social ou cultural do corpo e do movimento, vinculada a uma orientação pedagógico-política (PICH, 2014). Trata-se do objeto pedagógico da Educação Física na escola e circunscreve as seguintes práticas corporais: jogos, brincadeiras, danças, lutas, ginásticas, esportes (SOARES et al., 1992).
} 
de vergonha. A nota era resultado exclusivo do desempenho do aluno em testes físicos ou das habilidades esportivas, ou seja, se o aluno tinha um ótimo rendimento sua nota era máxima.

Ramalho et al. (2012) confirmam os apontamentos de Darido (2012), ao identificarem que a competência físico-cinestésica mostrou-se preponderante nas avaliações da maioria dos professores, com destaque para o desempenho dos alunos. Para além disso, também não encontraram coerência entre os critérios e indicadores de avaliação com os conteúdos descritos nos planos de ensino. Desse modo, constatou-se, na prática pedagógica, a falta da inter-relação entre os objetivos, os conteúdos, os procedimentos de ensino e a avaliação.

Apesar dos apontamentos supra, Darido (2003) sinaliza que, desde o final da década de 90 do século 20 e início dos anos 2000, muitos professores passaram a avaliar os alunos por meio da observação da motivação e interesse nas/pelas aulas. Isso pode demonstrar uma nova configuração da concepção de avaliação para a Educação Física escolar, e a mesma autora considera "[...] que essa é uma mudança positiva, porém insuficiente para ajudar o aluno a aprender Educação Física e incorporá-la na sua vida" ( $p$. 129).

Afinal, como nos incita a refletir Vaz (2017, p. 97-98),

Se pretendemos que as crianças aprendam aspectos de um elemento da cultura - saltar em suas várias possibilidades, por exemplo - não podemos dizer depois, simplesmente, que a aula transcorreu bem, que os pequenos colaboraram, que gostaram das atividades, etc. Precisamos perguntar, sem desconsiderar os itens anteriores, se elas aprenderam, no transcurso das aulas, o conteúdo cultural que ali estava sendo mediado.

Ampliando ainda mais os desafios correspondentes à avaliação na Educação Física escolar, nos anos iniciais do Ensino Fundamental (10 ao 30 ano) há certa crença de que os alunos aprendem na imobilidade, como denuncia Freire (1997), separando o ensino da escrita e da leitura do movimento corporal. Como destaca o autor, a criança é especialista em movimento e, por meio dele, constrói suas relações com o mundo e seus processos de significação.

Com base nestes apontamentos é que nos indagamos: Como os professores que estão atuando junto aos anos iniciais do Ensino Fundamental (1ำ ao 3ㅇ ano) com Educação Física estão pensando a avaliação? Por conta desta interrogação, os objetivos do presente artigo foram identificar e analisar as perspectivas de professores de Educação Física sobre a avaliação nos anos iniciais do Ensino Fundamental.

\section{PERCURSO METODOLÓGICO}

O estudo teve como orientação a abordagem de investigação qualitativa (BOGDAN; BIKLEN, 1994) e centrou-se na pesquisa exploratória (SAMPIERI; COLLADO; LUCIO, 2013).

A coleta deu-se por meio de entrevista semiestruturada (LÜDKE; ANDRÉ, 2012), envolvendo a seguinte pergunta: O que você avalia nas suas aulas de Educação Física escolar? Por quê? 
Os participantes do estudo foram 30 professores atuantes em escolas públicas da rede estadual de São Paulo, rede municipal e rede particular de ensino de uma cidade do interior paulista, sendo 9 homens e 21 mulheres. Sobre a questão da faixa etária, verificamos uma média de idade de 36 anos entre os participantes.

Em relação à formação dos professores, 21 deles formaram-se na década de 2000, 6 concluíram sua Graduação na década de 90 , enquanto 3 concluíram sua formação inicial na década de 80 do século 20 .

A respeito do tempo aproximado de atuação nos pautamos em Huberman (1995), que considera como início da carreira o tempo compreendido entre o primeiro e o sexto ano de exercício profissional. Assim definimos dois grupos: professores iniciantes e professores experientes. Do total de professores, especificamente atuando do 1음 ao 3응 anos do Ensino Fundamental, 17 eram professores iniciantes e 13 experientes.

Vale destacar que todos os professores aceitaram participar da pesquisa assinando o Termo de Consentimento Livre e Esclarecido. O referido trabalho foi aprovado pelo Comitê de Ética da universidade envolvida sob o Parecer CAEE - 40984815.0.0000.5398.

Dentre os procedimentos de análise dos dados, utilizamos a proposta de Gomes (2002), a qual apresenta os seguintes passos para sua operacionalização: a) Ordenação dos dados: faz-se o mapeamento de todos os dados obtidos no trabalho de campo (transcrição das gravações, releitura do material, organização dos relatos e dos dados da entrevista); b) Classificação dos dados: com base no que é relevante nos textos, são elaboradas os/as eixos/categorias específicas; c) Análise final: estabelecimento de articulações entre os dados e os referenciais teóricos da pesquisa, respondendo às questões investigadas com base nos objetivos.

Por meio de uma atenta leitura de todo o material, foram considerados os elementos mais recorrentes nas falas dos participantes e relacionados aos objetivos da pesquisa, dando visibilidade às perspectivas dos professores sobre a avaliação na Educação Física escolar.

Alguns fragmentos dos depoimentos dos professores foram apresentados de modo a dar mais relevo às reflexões resultantes da pesquisa. Estes aparecem identificados por nomes fictícios seguidos das datas de realização das entrevistas.

\section{RESULTADOS E DISCUSSÕES}

Dos dados identificados é possível afirmar que foi evidenciada uma convergência entre os discursos dos docentes com a construção do que se estabeleceu no final da década de 90 do século 20 por conta dos Parâmetros Curriculares Nacionais (PCNs) (BRASIL, 1997, 1998), especialmente no correspondente às dimensões dos conteúdos: conceitual, procedimental e atitudinal.

É eu avalio na verdade assim... é... a participação prática deles nos conteúdos que a gente propõe... que seria uma avaliação procedimental... as atitudes que são os comportamentos... como eles é... se tratam entre eles o respeito entre colegas respeito entre professor... o posicionamento deles nos jogos nos esportes... (JULIANA, 27/3/2015, grifos nossos). 
Ah... eu analiso o atitudinal ou seja... comportamental procedimental e o... conceitual sempre esses três [...] a gente acaba puxando mais nos procedimentais [...] conceitual [...] conhecer [...] ter o conhecimento ter o conceito [...] então, assim, claro que eu tenho bem importância pro conceito mais bem assim de leve, bem só pra ter conhecimento... se for afundar mesmo... pra eles o importante é... a vivência motora; eu acho mais importante a vivência motora (ALINE, 21/3/2015, grifos nossos).

Influenciados por Coll et al. (2000), neste processo de construção dos PCNs a área da Educação Física escolar passou a destacar as dimensões de conteúdo, compreendendo que seu ensino deveria ir além da dimensão procedimental (saber fazer) e envolver também as dimensões atitudinal (saber ser) e conceitual (saber sobre).

Tal perspectiva retira da Educação Física o papel exclusivo de ensinar a fazer algo (jogar, dançar, brincar, por exemplo), ampliando seu compromisso com as aprendizagens correspondentes ao saber sobre os temas deste componente curricular como também as relações entre os alunos e alunos-professor, envolvendo aqui as questões de comportamento e ética. Esta consideração das dimensões dos conteúdos, para a qual podemos notar uma reconfiguração do ensino da Educação Física escolar, já era defendida por acadêmicos da área antes dos PCNs (BETTI, 1994; BRACHT, 1996).

Com relação ao o que especificamente os professores avaliavam, verificamos que 25 , dos 30 professores, deram destaque à avaliação dos conhecimentos relacionados às atitudes e comportamentos dos alunos. Alguns fragmentos explicitam este foco:

Nas minhas aulas eu avalio... é... a participação deles [...] se eles estão motivados a realizar... as aulas... (MARIA, 25/3/2015, grifos nossos).

Bom eu avalio... como ele se relaciona com os outros durante essa atividade e também é a participação no geral... o desenvolvimento e a participação nas aulas; então isso é o foco principal da minha avaliação (SUZANA, 14/3/2015, grifos nossos).

Constatamos um predomínio dos elementos atitudinais em relação aos aspectos motores e conceituais. Resultados semelhantes foram encontrados no trabalho de Vargas (2017), indicando que os docentes tendem a valorizar essencialmente o campo afetivo das relações em detrimento do cognitivo e/ou psicomotor das aprendizagens. Macedo, Maximiano e Santos (2011) também identificaram que a avaliação dos professores se centralizava no comportamento e atitude dos alunos.

Tais resultados e alinhamentos com as pesquisas apresentadas podem nos conduzir a algumas indagações, quais sejam: A questão da participação nas aulas não seria uma condição anterior à avaliação? Precisaríamos nos perguntar: Como o aluno aprende se ele não participa da aula?

Como defendem Fernandes e Greenville (2007), e com os quais concordamos, a participação nas aulas de Educação Física é uma obrigatoriedade, uma vez que a mesma é um componente curricular amparado por lei. Além disso, a particularidade do componente curricular Educação Física, diferente da grande maioria dos outros componentes, está na sua caracterização pela demanda pelo movimento por parte do aluno (seja jogando, brincando, dançando, fazendo ginástica, lutando, por exemplo). 
Considerando que o que se avalia está intimamente ligado com o que se ensina, a confusão estabelecida quando se avalia a participação do aluno na aula pode nos conduzir a becos sem saída com relação às finalidades da Educação Física na escola, posto que, com tal dinâmica, o professor tende a se perder sobre o que, especificamente, o aluno deveria aprender.

Um dos perigos desta orientação está, como destacou Devide (2002), em estabelecer como referência para a aula a satisfação da criança e não o uso potencial dos conteúdos desenvolvidos e suas diferentes possibilidades para o ensino e a aprendizagem de aspectos sociocognitivos.

Pesquisas como as de Fernandes e Greenville (2007) e Farias, Shigunov e Nascimento (2002), vêm apontando que, na maioria das vezes, os alunos acabam sendo avaliados apenas pela participação nas atividades propostas pelos docentes. Isso, por sua vez, tende a ser resultado de um processo disciplinador por parte dos docentes que, ao perceberem um afastamento dos alunos das aulas, lançam mão desta ação.

Já os aspectos que se referem aos modos como os alunos se relacionam entre si e com as regras das práticas corporais desenvolvidas em aula, o esforço, a força de vontade e a superação por eles manifestados, podem ser reconhecidos como elementos de aprendizagens e correspondem à aquisição de valores vinculados à solidariedade com o outro, no sentido de se sensibilizar e respeitar o colega e o professor. Como a aprendizagem implica, todavia, em mudança de comportamento, a manifestação do respeito ao outro não deveria se dar com base em cobrança ou exigência do professor, mas num sentido crítico e reflexivo, por exemplo, no qual os alunos fossem mobilizados a pensar sobre as várias diferenças entre os colegas (cor de pele, habilidades motoras, gênero), e estas implicações direcionadas para as diversas maneiras que os colegas experimentam as práticas corporais.

Os motivos pelos quais os professores justificam avaliar as atitudes dos alunos estão relacionados a um dos objetivos da Educação Física escolar e ao papel da escola: a formação como cidadão. Segundo Betti e Zuliani (2002), a Educação Física, historicamente, tem se proposto a atingir aspectos afetivos e sociais na formação da personalidade do aluno. Uma das professoras exemplifica esses aspectos atitudinais em uma de suas falas:

Bom, na verdade, na nossa disciplina de Educação Física são muitos objetivos... é uma amplitude muito grande de coisas que a gente é... tem o papel de fazer com que os alunos saibam os objetivos nossos... então eu acredito que... a gente primeira coisa é formar as crianças... formação de pessoas, de cidadãos que respeitem regras que saibam respeitar o próximo; então acho que os valores do esporte, em primeiro lugar respeito, superação, cooperação... (GABRIELA, 20/3/2015, grifos nossos).

Neste sentido, o professor ajuda a formar o aluno quando avalia valores como a ética, a solidariedade, a igualdade e a liberdade, de forma que o mesmo possa se tornar um cidadão que pense e reflita sobre os valores da sociedade, repudiando atitudes de preconceito e intolerância (GONZÁLEZ; BRACHT, 2012).

Por conseguinte, as razões pelas quais os docentes avaliam estes aspectos específicos das atitudes dos alunos também podem ser explicitadas no excerto a seguir: 
[...] porque tem muita criança que não consegue trabalhar em grupo que dá problema... quando está sozinha ele... tranquilo é um aluno bom, muitas vezes alunos que, às vezes, na sala não dão trabalho, mas na Educação Física são muito competitivos... né? Às vezes dá problemas de violência, de briga; então a gente avalia isso também (DAIANE, 22/3/2015, grifos nossos).

Percebemos que os professores têm uma preocupação com o trabalho em grupo, na medida em que essa situação, por vezes, parece ser uma dificuldade para os alunos e que pode ser decorrente, por exemplo, das experiências que eles trazem de suas vidas, sua formação ética e valores morais, dificuldades na prática de alguns jogos ou mesmo no entendimento das regras.

Durante as atividades proporcionadas nas aulas de Educação Física, os alunos são colocados em muitas situações de desafios, e a avaliação dos aspectos atitudinais ocorre, na maioria das vezes, a partir desses conflitos e na resolução dos problemas. De acordo com Betti e Zuliani (2002), "Os jogos e esportes em geral constituem excelente oportunidade para observar o comportamento social dos alunos: coopera-se com os demais companheiros de equipe, se respeita as limitações impostas pelas regras, etc." (p. 80).

Ainda orientado pelo mesmo ponto de vista, Schühli (2008) vai apontar que nas vivências dos jogos, brincadeiras, esportes, lutas, danças é que os alunos mais se deparam com os desafios no âmbito dos valores, pois é neste momento que irão conviver com a vitória e a derrota, alimentando sentimentos diversos, como alegria, medo, superação e tristeza, que se expressam em seus comportamentos na relação consigo próprios e com o outro.

Esses aspectos relacionados ao comportamento dos alunos foram sinalizados por um dos professores:

Bom, a avaliação eu... avalio todo o momento... desde quando eu entro em sala de aula... até pra esperar fazer o silêncio... esperar até a chamada e eu... já é uma oportunidade de você avaliar questão comportamental questão da socialização com os alunos... vamos supor que um objetivo de um jogo no 10 ano... jogo cooperativo... que um dos objetivos é melhorar a relação entre os alunos. Isso já aconteceu comigo... ter uma sala muito violenta; brigava xingava por pouco e aí eu falei: eu vou esquecer um pouquinho o que eu tinha planejado e a partir desse bimestre eu vou trabalhar os jogos cooperativos pra introduzir questão de respeito educação, tudo... e... eu já avaliava desde quando eu chegava... na sala eu já percebia e eu tive a felicidade, e por isso eu te falo de ver essa evolução... evolução com jogos cooperativos; não foi bem de um dia para o outro; isso não foi... foi um processo; demorei uns quatro cinco meses; é de um bimestre; depois eu tive até que estender um pouquinho mais essa questão; aí eu fui observando e, realmente, na observação... funcionava a avaliação e eu também já usei outras já no 30 ano; questão de registro... registro eu já fiz bastante (FRANCISCO, 1ㅇ/3/2015, grifos nossos).

Segundo Fernandes e Greenville (2007), tal apontamento coincide com um dos instrumentos avaliativos comumente encontrados na Educação Física escolar, que é a observação. 
Ainda que a avaliação dos alunos por meio da observação possa se revelar como um modo de considerar o desenvolvimento individual dos alunos e como vem se constituindo seu processo de aprendizagem com relação aos conhecimentos ensinados, não foram identificados, entre os professores por nós entrevistados, roteiros que orientassem essa dinâmica da observação. Isso parece sinalizar para uma demanda importante e que poderia contribuir com avaliações menos genéricas, oferecendo, de fato, informações relevantes para os docentes tanto daquilo que os alunos estão ou não aprendendo quanto das estratégias de ensino empreendidas pelos professores.

Como já apontado anteriormente, balizados pelas dimensões dos conteúdos propostas por Coll et al. (2000) e utilizadas pelos PCNs (BRASIL, 1997, 1998), 15 professores destacaram a avaliação de elementos correspondentes às questões corporais e de movimento:

Oh... é... o que eu avalio... os movimentos corporais através da prática... (HELENA, 20/3/2015, grifos nossos).

Bom eu avalio principalmente o comportamento de disciplina ... que eu acho que é mais palpável assim... é quanto ao gesto motor... (ROSE, 25/2/2015, grifos nossos).

Tais respostas estabelecem certa aproximação com os estudos de Silva, Moura e Pereira (2015), que buscaram investigar a compreensão dos professores de Educação Física em relação à avaliação da aprendizagem nos anos iniciais do Ensino Fundamental. Quando indagados sobre o que avaliavam, foram enfatizadas as habilidades motoras, evidenciando predomínio motor nas aulas de Educação Física.

No contexto destes resultados podemos dialogar com duas vertentes bastante opostas da Educação Física escolar.

A primeira delas relaciona-se com as produções em defesa de um ensino voltado para o desenvolvimento de habilidades motoras padronizadas que partiriam dos movimentos mais rudimentares até aqueles vinculados às práticas esportivas. Tal proposição foi bastante difundida pela obra de Tani et al. (1988), intitulada "Educação Física escolar: fundamentos de uma abordagem desenvolvimentista".

Para Nunes e Rúbio (2008), nesta abordagem os objetivos seriam alcançados a partir da aprendizagem de habilidades motoras respeitando as características do comportamento motor dos alunos. Os conteúdos deveriam seguir uma ordem de habilidades das mais simples (fundamentais) para as mais complexas (específicas), oferecendo variadas oportunidades de movimento aos alunos a fim de ampliar seu repertório motor, permitindo-lhes melhor trânsito social.

A segunda vertente, em oposição à primeira, irá defender que não cabe à Educação Física o foco exclusivo no desenvolvimento de habilidades motoras e esportivas, mas tratar das representações e práticas sociais que constituem a cultura corporal de movimento (BRACHT, 2010). Neste sentido, Kunz (1994) irá sinalizar para a preocupação com o humano que se movimenta e não com o movimento em si, uma vez que o "se movimentar" (expressão utilizada pelo autor) envolve sempre uma conduta para algo, uma intencionalidade do sujeito que se materializa em situações concretas e, portanto, é repleta de sentidos e significados. 
Com base nesse entendimento, González e Schwengber (2012) destacam o se-movimentar com base em uma experiência de movimento voltada para a exploração do corpo e as possibilidades de ação do sujeito na relação com os objetos culturais.

Apesar das diferenças entre as vertentes, ambas alinham-se no reconhecimento de que as aulas de Educação Física envolvem um saber fazer dos alunos vinculado ao movimento. Esse modo de reconhecer a Educação Física também parece se fazer presente nos depoimentos dos professores.

Acredito que nessa faixa etária todas as atitudes dos alunos são avaliadas desde o desenvolvimento motor... como a forma de se relacionarem durante as atividades (HEITOR, 20/3/2015, grifos nossos).

[...] se ela sabe se movimentar, se ela consegue realizar movimentos simples, como andar, correr, saltar... a partir de todos esses movimentos (PAULO, 25/3/2015, grifos nossos).

A escola, entretanto, nem sempre convive de modo pacífico com esta configuração da Educação Física, uma vez que sua dinâmica se dá geralmente assentada em uma base cartesiana, na qual o que tem mais valor é o pensar e não o fazer. Ainda assim, as falas dos professores destacaram estes aspectos motores, de movimento e da realização do jogo como relevantes de se avaliar, posto que são ensinados nas aulas de Educação Física.

Apesar disso, ainda é um desafio para os professores de Educação Física avaliarem estes aspectos motores nas aulas. Fernandes e Greenville (2007) questionam como atribuir notas ao aprendizado de habilidades motoras, técnicas e de fundamentos das práticas corporais, isto é, devemos observar a realização de gestos corretos ou a quantidade de cestas ou gols marcados pelos alunos?

Na vertente de Tani et al. (1988), ganharia relevo avaliar os elementos motores que poderiam ser visualmente captados, ou seja, aquilo que o aluno demonstra realizando.

Betti e Zuliani (2002), estabelecendo relação com a segunda vertente, enfatizam que a avaliação das habilidades motoras, jogos, esportes, danças, ginásticas e práticas corporais, que se constituem enquanto conteúdos das aulas de Educação Física, precisa levar em consideração a qualidade dos movimentos apresentados pelo aluno e os conhecimentos a ele relacionados, estabelecidos e produzidos no desenrolar das aulas.

Como se pode notar, há uma configuração de uma avaliação que se vale do entendimento de movimento como deslocamento de um corpo no espaço e outra para um movimento carregado pela subjetividade humana, e que, por isso, é complexo de ser captado exclusivamente pela observação. Isso releva que a apropriação deste saber fazer por parte dos alunos transita num campo nem sempre possível de ser captado visualmente ou por observação por parte do professor, na medida em que envolve um saber orgânico (BETTI, 1994) encharcado de subjetividade e que só é construído pela vivência individual do movimento.

Acessar este saber por meio de manifestações orais dos alunos em rodas de conversa, narrativas em formato de desenhos e narrativas escritas, como sugerem Fabri, Rossi e Ferreira (2016), pode ser um recurso valioso para auxiliar o professor nos pro- 
cessos avaliativos dos alunos, dando condições para juntar os elementos subjetivos e objetivos que demarcam essa relação humana com o movimento trazido pelas práticas corporais.

Nesse contexto, cabe destacarmos os motivos pelos quais os professores avaliam o "se-movimentar" dos alunos:

[...] junto com isso se eu estou ampliando o repertório motor dos alunos... isso de 1 을 3 o ano... então se eu penso uma atividade de correr com deslocamento pra diversos lados por exemplo... eu tenho que avaliar se todos estão conseguindo fazer isso, se tem algum com dificuldade, se não tem... e se tiver, eu pensar alguma variação, alguma coisa pra poder estimular que esse aluno, pelo menos, consiga também adquirir esse recurso... numa brincadeira... (JULIANO, 11/3/2015, grifos nossos).

Eu avalio o desenvolvimento do aluno... através de alguns jogos... exercícios... registros... sendo que observo como o aluno se sai quando realiza... o mesmo jogo várias vezes... como ele se saiu na primeira vez... como ele se saiu na segunda... na terceira... então como ele melhorou, como ele se desenvolveu... o que ele aprendeu... para que eu possa melhorar minha forma de ensinar (ANA JULIA, 27/2/2015, grifos nossos).

Os professores destacaram que a avaliação dessa dimensão motora é importante para reavaliar o próprio trabalho, ampliar o repertório motor, avaliar as dificuldades de aprendizagem e também avaliar o progresso e a evolução dos alunos.

Dessa maneira, a avaliação pode e deve oferecer ao professor elementos para uma reflexão contínua sobre a sua prática no que se refere à escolha de competências, objetivos, conteúdos e estratégias. Ela auxilia na compreensão de quais aspectos devem ser revistos, ajustados ou reconhecidos como adequados para o processo de aprendizagem individual e de todo o grupo de alunos (DARIDO, 2012). Além disso, permite que o professor conheça o progresso de seus alunos e as dificuldades que encontram na aprendizagem dos conteúdos, de modo que possam adaptar e orientar seu trabalho docente para ajudar a satisfazer as necessidades dos estudantes (MÉNDEZ, 2013).

Ao analisarmos os dados correspondentes aos elementos relativos à avaliação da dimensão conceitual, somente três professores indicaram isso em suas falas:

[...] questão da compreensão da atividade [...] uma outra conversa com eles é... perguntando olha o que nós fizemos hoje? O que nós aprendemos? [...] é o momento dessa compreensão do aprendizado através não da escrita, mas através de desenhos... (CARLOS, 26/3/2015, grifos nossos).

[...] uma atividade no começo da aula retomando o conteúdo daquela outra aula... eu quero vê o que ficou daquilo, do conteúdo que eu passei; o que ele conseguiu... APRENDÊ ou APRENDER... qual foi... se pra ele teve significado... aquela aprendizagem... é... eu penso que uma forma de avaliar é se pra aquele aluno aquilo foi significativo ou não... (HELOISE, 15/3/2015, grifos nossos).

[...] que eles saibam diferenciar as brincadeiras de jogos (MICHELE, 27/3/2015, grifos nossos). 
Esses conteúdos envolvem a compreensão, a reflexão, a análise e a comparação, por isso é necessário acessar outra esfera do saber. Isso porque, durante o processo de aprendizagem, o aluno precisa adquirir informações e vivenciar situações-problema que o conduzam a novos conhecimentos, partindo de seus conhecimentos prévios para a elaboração de novos conceitos. O conhecimento prévio diz respeito aos saberes que os alunos já possuem; sendo assim, ao iniciar a abordagem de um conteúdo o professor poderá identificar o que sua turma efetivamente conhece sobre o que será tratado.

Em defesa deste saber de natureza conceitual na Educação Física, Fensterseifer e González (2013, p. 39) ensinam que: "Nosso compromisso resumia-se a um fazer, e hoje somos desafiados a construir um saber 'com' esse fazer. Mais que isso, pensar um saber que se desenvolve ao longo dos anos escolares em complexidade e criticidade [...]". A partir daí é possível perceber a articulação conteúdo/objetivo. Para Gallardo (2009, p. 55, grifo do autor), "A riqueza do aprendizado propiciado pelas manifestações da cultura corporal não se esgota em sua realização pura e simples. É de fundamental importância que as crianças aprendam a refletir sobre sua prática, e não apenas vivenciá-la".

Como exemplo, podemos destacar a fala da professora Michele, ao tematizar nas aulas a diferença entre as brincadeiras e os jogos. Além da vivência e experimentação dessas práticas corporais, também leva os alunos a refletirem sobre o conceito de jogo e brincadeira. Fernandes e Greenville (2007, p. 137, grifo dos autores) enfatizam isso afirmando que "[...] este vivenciar deve vir acompanhado de um significado de práxis, para que o aluno além de vivenciar, coloque em prática, através de uma reflexão também teórica, o que foi aprendido nas aulas, bem como seus conhecimentos e experiências pessoais adquiridas fora da escola".

Sob este ponto de vista, a avaliação na dimensão conceitual consiste em observar o uso dos conceitos em trabalhos de equipe, debates, exposições, nos diálogos entre os alunos e entre o professor e os alunos (DARIDO; SOUZA JUNIOR, 2008). Além disso, o aluno pode ser avaliado sobre o entendimento de um tema por meio de uma avaliação oral, uma autoavaliação ou mesmo uma discussão na roda de conversa, uma observação durante as aulas, em trabalhos e vídeos, ou ser solicitada a sua interpretação dos conceitos trabalhados por meio dos registros de desenhos ou escrito, pequenos textos individuais e em grupos e produção de cartazes.

Pelo menos no campo do discurso, os 30 professores por nós entrevistados alinham-se a uma mudança de concepção de Educação Física e da aptidão física para a cultura corporal de movimento. Daí podemos depreender que os professores entrevistados demonstraram reconhecer que há outros elementos, além do próprio movimento, que precisam ser avaliados nas aulas de Educação Física e, consequentemente, ensinados. Por esta via, percebemos uma valorização da possibilidade de expressão dos alunos a partir de diferentes linguagens: corporal, escrita e falada, ou seja, construções socioculturais que abrigam significados datados (BRACHT, 2010).

Para a Educação Física escolar, as aprendizagens dos movimentos são importantes no exercício da autonomia dos alunos para analisar, criticar e vivenciar os processos em ação. Desse modo, os momentos da Educação Física fundamentam-se em objetivos pedagógicos claros e planejados, que compreendam meninas, meninos e seus movi- 
mentos numa perspectiva ampla, tomando por base este repertório composto pelas ações de cada sujeito nas suas relações com o outro e com o conhecimento vivido em diferentes contextos.

Para isso, reforçamos a importância de o professor ter acesso, também, aos conhecimentos referentes à compreensão dos tempos infantis e às diferentes formas de assegurar os direitos e objetivos de aprendizagem e desenvolvimento inerentes às experiências, saberes e fazeres em Educação Física nas escolas. Com tais pressupostos, os alunos terão condições de construir competência que os permitam apreciar, executar e criar conhecimentos relativos à cultura corporal bem como refletir sobre eles (BRASIL, 2012).

Em relação ao que vem sendo publicado e produzido sobre a avaliação em Educação Física (SOARES et al., 1992; FERNANDES; GREENVILLE, 2007; MELO; FERRAZ; NISTA-PICCOLO, 2010; MACEDO et al., 2011; GONZÁLEZ; SCHWENGBER, 2012; SANTOS; MAXIMIANO, 2013; SANTOS et al., 2015; SILVA; MOURA; PEREIRA, 2015; VARGAS, 2017), os processos avaliativos devem superar a utilização apenas da observação do comportamento, do desempenho dos movimentos dos alunos e a participação nas aulas, mas também contemplar a produção de registros por meio de desenhos, da escrita, apresentações de trabalhos, autoavaliação, exposições em grupos, diálogos entre professor e alunos, dentre outros.

Por fim, os instrumentos avaliativos têm como tarefa gerar novas oportunidades de aprendizagem e fornecer dados essenciais tanto para o professor, como um meio de aperfeiçoar seus modos de ensinar, quanto para o aluno, pois permitem reconhecer as dificuldades e apontar as possibilidades num constante aprendizado. Logo, é necessário que as atividades sejam significativas, que proporcionem aos alunos novas experiências para aprender, para melhorar seu desempenho e para refletir sobre seu próprio trabalho.

Assim como Bracht (2010), entendemos que as práticas avaliativas na Educação Física escolar não se valem por elas mesmas, pois, ainda que o cenário deste estudo tenha mapeado um conjunto variado de formas de avaliar, estas são apenas referências para o que se ensina. É importante, todavia, entender que a avaliação como um processo pedagógico formativo só se configura efetivamente a partir de determinadas intenções. Assim, o tipo de abordagem, mais do que simplesmente a eleição de uma determinada avaliação, é que vai definir o que se espera que o aluno aprenda.

\section{CONSIDERAÇÕES FINAIS}

Ao considerarmos as concepções dos professores sobre o que avaliam nas aulas de Educação Física escolar, os mesmos dividem os focos de avaliação em: conhecimentos conceituais, procedimentais e atitudinais, com um predomínio dos elementos atitudinais em relação aos outros dois.

Os professores deram destaque à avaliação dos conhecimentos relacionados ao comportamento dos alunos, à participação nas aulas, à aquisição de valores, como o esforço, à força de vontade e à superação, ao trabalho em grupo e aos modos como eles se relacionam entre si e com as regras das práticas corporais. 
Quanto aos conhecimentos procedimentais e conceituais, os professores manifestaram relacionar a avaliação de elementos correspondentes às questões corporais nas aulas de Educação Física, envolvendo um saber fazer dos alunos vinculados ao movimento e um saber sobre esse fazer, valorizando a compreensão, a reflexão, a análise e a comparação dos conteúdos. Tais apontamentos parecem revelar uma ampliação de sentido e ações avaliativas por parte dos professores de Educação Física, podendo sinalizar, para a área, uma possível reconfiguração alinhada aos pressupostos da cultura corporal de movimento.

Um dos limites desta pesquisa, e que poderia ampliar nossas análises, seria o cruzamento das perspectivas dos professores com as práticas avaliativas desenvolvidas nas aulas: como eles fazem, onde registram e os instrumentos de avaliação da aprendizagem dos alunos.

Ressaltamos a necessidade de outros estudos relacionados à avaliação nas aulas de Educação Física em prol de alimentar uma melhor compreensão deste cenário, favorecendo a construção de outras formas de intervenção.

\section{REFERÊNCIAS}

BETTI, M. O que a semiótica inspira ao ensino da educação física. Discorpo, PUCSP, São Paulo, n. 3, p. 2545, 1994.

BETTI, M.; ZULIANI, L. R. Educação Física Escolar: uma proposta de diretrizes pedagógicas. Revista Mackenzie de Educação Física e Esporte, São Paulo, a. 1, n. 1, p. 73-81, 2002.

BOGDAN, R.; BIKLEN, S. Investigação qualitativa em educação: uma introdução à teoria e aos métodos. Trad. M. J. Alvarez, S. B. Santos e T. M. Baptista. Portugal: Porto Editora, 1994.

BRACHT, V. Educação Física no 1o grau: conhecimento e especificidade. Revista Paulista de Educação Física, São Paulo, Supl. 2, p. 23-28, 1996.

BRACHT, V. A Educação Física no Ensino Fundamental. In: SEMINÁRIO NACIONAL DO CURRÍCULO EM MOVIMENTO - PERSPECTIVAS ATUAIS, 1., 2010. Belo Horizonte. Anais [...]. Brasília: Ministério da Educação; Secretaria de Educação Básica, 2010. Disponível em: http://portal.mec.gov.br/index.php?option=com_ content\&view=article\&id=16110\&Itemid=936. Acesso em: 3 fev. 2012.

BRASIL. Secretaria de Educação Fundamental. Parâmetros Curriculares Nacionais: Educação Física. Brasília: MEC; SEF, 1997.

BRASIL. Secretaria de Educação Fundamental. Parâmetros Curriculares Nacionais: Educação Física. Brasília: MEC; SEF, 1998.

BRASIL. Ministério da Educação. Secretaria de Educação Básica. Elementos conceituais e metodológicos para definição dos direitos de aprendizagem e desenvolvimento do ciclo de alfabetização (10, 2o e 3ㅇ anos) do Ensino Fundamental. Brasília: MEC; SEB, 2012. Disponível em: http://portal.mec.gov.br/index. php?option=com_docman\&task=doc_download\&gid=12827\&ltemid=. Acesso em: 5 abr. 2014.

COLL, C. et al. Os conteúdos na reforma. Porto Alegre: Artmed, 2000.

DARIDO, S. C. Educação Física na escola: questões e reflexões. Rio de Janeiro: Guanabara Koogan, 2003.

DARIDO, S. C. A avaliação da educação física na escola. In: UNIVERSIDADE ESTADUAL PAULISTA. Prograd. Caderno de formação: formação de professores didática geral. São Paulo: Cultura Acadêmica, 2012. p. 127-140. V. 16.

DARIDO, S. C.; SOUZA JÚNIOR, O. M. Para ensinar educação física: possibilidades de intervenção na escola. 2. ed. Campinas: Papirus, 2008.

DEVIDE, F. P. Educação Física escolar no primeiro segmento do Ensino Fundamental: contribuições para um debate. Motrivivência, a. XIII, n. 19, p. 1-7, dez. 2002.

FABRI, E.; ROSSI, F.; FERREIRA, L. A. Episódios marcantes nas aulas de Educação Física. Movimento, Porto Alegre, v. 22, n. 2, 583-596, abr./jun. 2016.

FARIAS, G. O.; SHIGUNOV, V.; NASCIMENTO, J. V. do. O percurso profissional dos professores de Educação Física nas escolas. In: SHIGUNOV, V.; SHIGUNOV NETO, A. Educação Física: conhecimento teórico x prática pedagógica. Porto Alegre: Mediação, 2002. 
FENSTERSEIFER, P. E.; GONZÁLEZ, F. J. Desafios da legitimação da Educação Física na escola republicana. Horizontes - Revista de Educação, Dourados, MS, n. 2, v. 1, jul./dez. 2013.

FERNANDES, S.; GREENVILLE, R. Avaliação da aprendizagem na Educação Física escolar. Motrivivência, a. $X I X$, n. 28, p. 120-138, jul. 2007.

FREIRE, J. B. Educação de corpo inteiro: teoria e prática da Educação Física. 4. ed. São Paulo: Editora Scipione, 1997.

GALLARDO, J. S. P. Prática de ensino em Educação Física: a criança em movimento. São Paulo: FTD, 2009. GOMES, R. A. Análise de dados em pesquisa qualitativa. In: MINAYO, M. C. S. (org.). Pesquisa social: teoria, método e criatividade. Petrópolis: Vozes, 2002. p. 67-80.

GONZÁLEZ, F. J.; BRACHT, V. Metodologia do ensino dos esportes coletivos. Vitória: Ufes; Núcleo de Educação Aberta e a Distância, 2012. 126 p.

GONZÁLEZ, F. J.; FENSTERSEIFER, P. E. Entre o "não mais" e o "ainda não": pensando saídas do não-lugar da EF Escolar I. Cadernos de Formação RBCE, Campinas, v. 1, n. 1, p. 9-24, set. 2009.

GONZÁLEZ, F. J.; SCHWENGBER, M. S. V. Práticas pedagógicas em Educação Física: espaço, tempo e corporeidade. Erechim: Edelbra, 2012.

HUBERMAN, M. O ciclo de vida profissional dos professores. In: NÓVOA, A. (org.). Vidas de professores. 2. ed. Portugal: Porto Editora, 1995. p. 31-61.

KUNZ. E. Transformação didático-pedagógica do esporte. Ijuí: Editora Unijuí, 1994.

LÜDKE, M.; ANDRÉ, M. E. D. A. Pesquisa em educação: abordagens qualitativas. São Paulo: EPU, 2012.

MACEDO, L. R. et al. Práticas avaliativas das séries iniciais do ensino fundamental: diálogos com professoras de educação física. In: CONGRESSO ESPÍRITO-SANTENSE DE EDUCAÇÃO FÍSICA, 11., 2011, Vitória. Anais [...]. Vitória: Conesef, 2011. CD-ROOM. Disponível em: http://proteoria.org/modules/publisher/ item.php?itemid=44. Acesso em: 11 jul. 2018.

MACEDO, L. R.; MAXIMIANO, F. de L.; SANTOS, W. Avaliação na educação física escolar: uma análise da produção acadêmica. In: CONGRESSO ESPÍRITO-SANTENSE DE EDUCAÇÃO FÍSICA, 11., 2011, Vitória. Anais [...] Vitória: Conesef, 2011. CD-ROOM. Disponível em: http://proteoria.org/modules/publisher/item. php?itemid=43. Acesso em: 15 jul. 2018.

MELO, L. F.; FERRAZ, O. L.; NISTA-PICCOLO, V. L. O portfólio como possibilidade de avaliação na Educação Física escolar. Revista da Educação Física/UEM, Maringá, v. 21, n. 1, p. 87-97, 10 trim. 2010.

MÉNDEZ, J. M. A. O currículo como marco de referência para a avaliação educativa. In: SACRISTÁN, J. G. (org.). Saberes e incertezas sobre o currículo. Tradução Alexandre Salvaterra. Porto Alegre: Penso, 2013.

NUNES, M. L. F.; RÚBIO, K. O(s) currículo(s) da Educação Física e a constituição da identidade de seus sujeitos. Currículo Sem Fronteiras, v. 8, n. 2, p. 55-77, jul./dez. 2008.

PICH, S. Cultura corporal de movimento. In: GONZÁLEZ, F.; FENSTERSEIFER, P. E. (org.). Dicionário crítico de Educação Física. 3. ed. rev. e ampl. Ijuí: Ed. Unijuí, 2014. p. 163-165.

RAMALHO, M. H. da S. et al. Avaliação na Educação Física escolar: uma análise a partir do modelo de inteligência motora. Pensar a Prática, Goiânia, v. 15, n. 4, p. 821-1.113, out./dez. 2012.

SAMPIERI, R. H.; COLLADO, C. F.; LUCIO, M. del P. B. Metodologia de pesquisa. 5. ed. Porto Alegre: Penso, 2013.

SANTOS, W. et al. Avaliação na Educação Física escolar: reconhecendo a especificidade de um componente curricular. Movimento, Porto Alegre, v. 21, n. 1, p. 205-218, jan./mar. 2015.

SANTOS, W.; MAXIMIANO, F. L. Avaliação na Educação Física escolar: singularidades e diferenciações de um componente curricular. Revista Brasileira de Ciências do Esporte, Florianópolis, v. 35, n. 4, p. 883-896, out./dez. 2013. Disponível em: http://www.scielo.br/pdf/rbce/v35n4/06.pdf. Acesso em: 5 abr. 2014.

SILVA, F. F.; MOURA, S. E. W. B.; PEREIRA, R. S. A avaliação nos anos iniciais do Ensino Fundamental: um retrato da prática dos professores de Educação Física na rede pública municipal de Cuiabá. Pensar a Prática, Goiânia, v. 18, n. 2, abr./jun. 2015.

SCHÜHLI, M. S. Secretaria de Estado da Educação Superintendência de Educação. Diretoria de Políticas e Programas Educacionais Coordenação Estadual do PDE. Um novo olhar sobre avaliação em Educação Física escolar: os desafios das construções coletivas. Porto Amazonas, 2008. Disponível em: http://www. diaadiaeducacao.pr.gov.br/portals/pde/arquivos/1546-6. Acesso em: 5 abr. 2014.

SOARES, C. L. et al. Metodologia do Ensino de Educação Física. São Paulo: Cortez, 1992.

TANI, G. et al. Educação física escolar: fundamentos de uma abordagem desenvolvimentista. São Paulo: EPU, 1988. 


\section{Revistantexto \\ \&Educaçãoo}

Avaliação nos Anos Iniciais do Ensino Fundamental: Perspectivas de Professores de Educação Física

VARGAS, C. P. Avaliação na educação física escolar: tensões para além das epistemologias. Rev. Bras. Educ. Fís. Esporte, São Paulo, p. 819-834, out./dez. 2017.

VAZ, A. F. Avaliação em Educação Física na Educação Infantil: notas para discussão. Cadernos de Formação $R B C E$, p. 95-104, set. 2017. 